\title{
TESTING AN EMPIRICAL NOMOLOGY OF GLOBAL LOGISTICS PERFORMANCE FUNCTIONS
}

Framarz Byramjee, Indiana University of Pennsylvania, Indiana, Pennsylvania, U.S.A. Parimal Bhagat, Indiana University of Pennsylvania, Indiana, Pennsylvania, U.S.A. Jill Baumgardner, Indiana University of Pennsylvania, Indiana, Pennsylvania, U.S.A. Kevin Lhota, Indiana University of Pennsylvania, Indiana, Pennsylvania, U.S.A.

dx.doi.org/10.18374/JIBE-20-3.3

\begin{abstract}
This paper configures analytical relationships among pertinent operationalized variables based on logistics data of countries as trading entities in the dynamics of global transactional fulfillment. The thesis models a nomologically valid explication of factors influencing logistical effectiveness, with statistically significant and substantive implications of findings. Utilizing reliable secondary data mined from the World Bank Database on nations' logistics performance parameters, the discourse analyzes empirical effects of transportation infrastructure, consignments tracking ability, competitive order pricing, clearance process efficiency, and timely shipments delivery on logistics service quality and competence. Future research aims to bolster this model with effects of warehousing functions' elements and macroeconomic indicators on service quality.
\end{abstract}

Keywords: Logistics Functions, Secondary Data, Variables, Effects, Interactions, Significances 